\title{
A Study of Social Diversities and Humanities in Teaching Reading Texts through Project-Based Learning Approach (PBL)
}

\author{
Aye Pa Pa Myo \\ English Department, Yangon University of Education, Yangon, Myanmar \\ Email: Ayeaye134719@gmail.com
}

How to cite this paper: Myo, A.P.P. (2020) A Study of Social Diversities and Humanities in Teaching Reading Texts through ProjectBased Learning Approach (PBL). Open Access Library Journal, 7: e6585.

https://doi.org/10.4236/oalib.1106585

Received: July 6, 2020

Accepted: July 26, 2020

Published: July 29, 2020

Copyright $\odot 2020$ by author(s) and Open Access Library Inc.

This work is licensed under the Creative Commons Attribution International License (CC BY 4.0).

http://creativecommons.org/licenses/by/4.0/

(c) (i) Open Access

\begin{abstract}
Social diversities and humanities can be observed in the study of different languages. This paper has an attempt to teach the students selected reading texts prescribed from straightforward course book (C1) level. The main purpose of doing this search is to teach social diversities and humanities to the students via reading texts from straightforward course books in the EFL classrooms. This research took four weeks. Twenty-eight Fourth-Year (COE) students including fourteen boys and fourteen girls from Yangon University of Education were used as the sample in this research. It was conducted with project-based learning approach. Self-observation and interviewing in groups were used as research tools. Data were collected and analyzed with qualitative research method. Due to the findings from the research, language used in fourth year selected reading texts can reveal social diversities more than humanities to some extent, because the context in most of the reading texts emphasizes the social diversities. Nevertheless, language can reflect the social life which is bounded with social diversities and humanities in alternative ways. So, studying a target language or a foreign language is very beneficial not only for learners but also for teachers. In brief, all findings will be supportive for further research related to language, social diversities and humanities.
\end{abstract}

\section{Subject Areas}

Social Diversities and Humanities

\section{Keywords}

Humanities, Project-Based Learning Approach (PBL), Social Life, Social

Diversities, Straightforward Course Book (C1) Level 


\section{Introduction}

There is a relation between language and society in which humans live together happily. Otherwise, language is the part of a society and it can represent diversities and humanities of all people in this society. Different languages can show diverse societies and humanities. In similar way, different literature can show unequal themes and unequal attitudes of social diversities. On the other hand, reading and approaching literary texts or reading texts can give a chance to the readers to study social diversities and humanities. Besides, general customs and manners of people greatly differ in the social diversities. Social diversities and humanities can determine the caste system, class, religion, occupational patterns in a given territory. Studying different language can provide a chance to learn diverse societies and humanities. In EFL classrooms, learners can study social diversities and humanities from the targeted language which they have to learn in alternative ways, such as in listening, speaking, reading and writing.

In the previous research, "A National Survey of Instructional Strategies Use Teach Information Systems Courses: An Exploratory Investigation” named Mr. Djajalaksana from University of South Florida did a research related to social diversities and humanities based on the reading texts to describe humanities, fine arts, social sciences outside the classroom by giving reading tasks to the students. The data obtained from this research were collected and analyzed with qualitative research method. According to outcomes from this research, students did the complete reading assignments. They studied social diversities and humanities to some extent.

\subsection{Objectives}

There are two parts in this section. They are general objective of the study and specific objectives of the study.

General Objective of this Study

- To investigate social diversities and humanities from selected reading texts prescribed from straightforward course book (C1) level through project-based learning approach in the EFL classrooms

Specific Objectives of the Study

- To teach the students selected reading texts prescribed from straightforward course book (C1) level through project-based learning approach in the EFL classrooms

- To encourage in studying the social diversities and humanities from these texts through this approach

Research Questions

- How can the students be taught selected reading texts prescribed from straightforward course book (C1) level through project-based learning approach in an EFL classroom?

- How can they study the social diversities and humanities from these texts through this approach? 


\subsection{Significance of the Study}

This research paper is essential not only for the students but also for the teachers to notice social diversities and humanities by studying reading texts prescribed from Straightforward course book (C1) through project-based learning approach in the EFL classrooms.

\subsection{Imitations of the Study}

This research paper was concerned with the study of reading texts prescribed from straightforward course book (C1) to notice social diversities and humanities in the EFL classrooms. This study was done only with twenty-eight Fourth-Year (COE) students including fourteen boy students and fourteen girl students from Yangon University of Education in Kamaryut Township, Yangon Region.

\subsection{Previous Study}

In the previous research, "A National Survey of Instructional Strategies Use Teach Information Systems Courses: An Exploratory Investigation” by Yenni M. Djajalaksan from University of South Florida did a research related to social diversities and humanities based on the reading texts to describe humanities, fine arts, social sciences outside the classroom by giving reading tasks to the students. This research took a semester. Fifteen students were trained to read the texts for the purpose of investigating social diversities and humanities from these reading texts. This study examined the instructional strategies used most frequently in the information systems discipline and was inspired by Shulman's (2005) concept of signature pedagogies the unique but pervasive ways of teaching within a discipline or profession.

This study employed a web-based survey of all information systems faculty members in the United States listed in the Association of Information Systems membership directory (695 valid responses were obtained from 2835 eligible participants, $24.4 \%$ response rate). The research used the original questionnaire identifying 52 different instructional strategies as the research tools so that a profile of commonly employed teaching practices can be identified whether there are identifiable signature pedagogies in the discipline of Information Systems (IS) or not. Data were collected and analyzed with the descriptive statistics. Due to the findings from the research, actor analysis of the survey items and multiple regression of eight independent variables were used to predict frequency of instructional strategy used.

\section{Literature Review}

\subsection{Social Diversity}

According to Wikipedia [1], it means understanding that each individual is unique, and recognizing our individual differences. These can be along the dimensions of race, ethnicity, gender, sexual orientation, socio-economic status, 
age, physical abilities, religious beliefs, political beliefs, or other ideologies.

\subsection{Cultural Diversity}

According to Wikipedia [1], it is the quality of diverse or different cultures, as opposed to monoculture; it can be argued that cultural diversity may be vital for the long-term survival of humanity; and that the conservation "Cultural protection" or "cultural exception" defends the social vision of culture against its commercialization

In sociology and political studies, diversity is the degree of differences in identifying features among the members of a purposefully defined group, such as any group differences in racial or ethnic classifications, age, gender, religion, philosophy, physical abilities, socioeconomic background, sexual orientation. It means understanding that each individual is unique, and recognizing our individual differences. These can be along. the dimensions of race, ethnicity, gender, sexual orientation, socio-economic status, age, physical abilities, religious beliefs, political beliefs, or other ideologies.

\subsection{Humanities}

According to www.gladstone.uoregon.edu [2] the humanities are studies about human culture, such as literature, philosophy, and history. The humanities provide general knowledge about the best accomplishments of human beings throughout history.

The concept of diversity encompasses acceptance and respect. It means understanding that each individual is unique, and recognizing our individual differences. These can be along the dimensions of race, ethnicity, gender, sexual orientation, socio-economic status, age, physical abilities, religious beliefs, or other ideologies. It is the exploration of these differences in a safe, positive, and nurturing environment. It is about understanding each other and moving beyond simple tolerance to embracing and celebrating the rich dimensions of diversity contained within each individual.

The humanities are academic disciplines that seek to understand, appreciate and critique the human conduction in all its depth and range of meaning. They, in varied ways, consider the "big questions", both of the contemporary and the perennial, and with these understandings and methodologies engage civic life, both locally and globally, to address the challenges faced by humanity.

According towww.adstone.uoregon.edu [2] the term "humanities" includes, but is not limited to, the study of the following: language, both modern and classical; linguistics; literature; history; jurisprudence; philosophy; archaeology; comparative religion; ethics; the history, criticism and theory of the arts; those aspects of social sciences which have humanistic content and employ humanistic methods; and the study and application of the humanities to the human environment with particular attention to reflecting our diverse heritage, traditions, and history and to the relevance of the humanities to the current conditions of 
national life (emphasis added), to both the unique and diverse as well as the national and shared in common

\subsection{Project-Based Learning Approach (PBL)}

According to Wikipedia [3], project-based learning (PBL) is a student-centered pedagogy that involves a dynamic classroom approach in which it is believed that students acquire a deeper knowledge through active exploration of real-world challenges and problems. It is a style of active learning and inquiry-based learning.

Markham. T (2011) [4] described project-based learning (PBL) thus: PBL integrates knowing and doing. Students learn knowledge and elements of the core curriculum, but also apply what they know to solve authentic problems and produce results that matter. PBL students take advantage of digital tools to produce high quality, collaborative products. PBL refocuses education on the student, not the curriculum - a shift mandated by the global world, which rewards intangible assets such as drive, passion, creativity, empathy, and resiliency. These cannot be taught out of a textbook, but must be activated through experience.

According to Blumenfeld et al. 1991 [5], project-based learning is a comprehensive perspective focused on teaching by engaging students in investigation. Within this framework, students pursue solutions to nontrivial problems by asking and refining questions, debating ideas, making predictions, designing plans and/or experiments, collecting and analyzing data, drawing conclusions, communicating their ideas and findings to others, asking new questions, and creating artifacts.

According to Blumenfeld et al. 1991 [5], the basis of PBL lies in the authenticity or real-life application of the research. Students working as a team are given a "driving question" to respond to or answer, then directed to create an artifact (or artifacts) to present their gained knowledge. Artifacts may include a variety of media such as writings, art, drawings, three-dimensional representations, videos, photography, or technology-based presentations.

In Peer Evaluation in Blended Team Project-Based Learning: What Do Students Find Important? Hye-Jung \& Cheolil (2012) [6] described "social loafing" as a negative aspect of collaborative learning. Social loafing may include insufficient performances by some team members as well as a lowering of expected standards of performance by the group as a whole to maintain congeniality amongst members. These authors said that teachers tend to grade the finished product only; the social dynamics of the assignment may escape the teacher's notice

\subsection{Roles of Instructors or Teachers}

According to http://www.ascd.org/ [7] in Project Based Learning, instructor's role is a facilitator. He or she does not relinquish the control of the classroom or student learning but rather develop an atmosphere of shared responsibility. The 
instructor must structure the proposed question/issue so as to direct the student's learning toward content-based materials. The instructor must regulate student success with intermittent, transitional goals to ensure student projects remain focused and students have a deep understanding of the concepts being investigated.

\subsection{Roles of Students}

According to Boss, S., \& Krauss, J. (2007) [8], the students are held accountable to these goals through ongoing feedback and assessments. The ongoing assessment and feedback are essential to ensure the student stays within the scope of the driving question and the core standards the project is trying to unpack.

According to Perrault, Evan K [9] formative assessments are used in order to be transparent to parents and students, you need to be able to track and monitor ongoing formative assessments, that show work toward that standard. The instructor uses these assessments to guide the inquiry process and ensure the students have learned the required content.

According to Boss, S., \& Krauss, J. (2007) [8], the role of the students is to ask questions, build knowledge, and determine a real-world solution to the issue/question presented. Students must collaborate expanding their active listening skills and requiring them to engage in intelligent focused communication. Therefore, the students are allowed to think rationally how to solve problems. PBL forces students to take ownership of their success.

\section{Research Methodology}

In this section, there are three parts. They are as follows:

\subsection{Sample}

To do this research, twenty-eight students were randomly chosen as the sample or participants. There were fourteen boy students and fourteen girl students. They were students who were attending the Fourth Year (COE) class from Yangon University of Education. They were at the ages between 15 and 20 having different fundamental language competency and proficiency.

\subsection{Instrumentation}

To do this research, as research tools, interviewing and reading catalogues were used.

\subsection{Procedure}

In this research, there are altogether four steps. They are as follows:

1) Planning and designing

To do this research, eight reading texts were selected to train the students who were grouped into four. Each group had seven students having both males and females. The research took four weeks. It was conducted through project-based 
learning approach (PBL). According to project-based learning approach (PBL), the students were given the respective projects group by group. In first two weeks, selected four groups were provided with four reading texts to investigate social diversities and humanities as well as given feedback to them. In second two weeks, selected four groups were provided with next four reading texts to investigate social diversities and humanities as well as given feedback to them again. After that, the teacher discussed with all facts and data related with social diversities and humanities from all eight reading texts they were assigned to read and prescribed from straightforward course book (C1) level. Then, all data were collected and analyzed with qualitative research method.

Sample Reading (Catalogue/Record)

\begin{tabular}{ccccc}
\hline No & Group. No & Name of Reading Texts & $\begin{array}{c}\text { Findings-(Social Diversities } \\
\text { and Humanities) }\end{array}$ & $\begin{array}{c}\text { Remarks } \\
\text { (Most/Least) }\end{array}$ \\
\hline 1 & A & Celebrity heroes & social diversities & Most \\
3 & B & Chy are humans good? & social diversities/humanities & Most \\
4 & D & A Good Job & Growing Up & social diversities \\
\hline
\end{tabular}

Sample Questions for interviewing

a) What is the main idea of the reading text that you are now reading?

b) What do you get from the reading text that you are now reading?

c) What are the supporting ideas you get from the reading text now you are reading?

d) Are there any facts defined social diversities and humanities? What are they?

e) How will you mention what they are?

f) Do you have anything to say about social diversities and humanities besides the reading text that you are now reading?

g) How do you feel when you read these reading texts?

2) Giving four reading texts to the students to investigate social diversities and humanities and giving feedback to them

In the first two weeks, students from four groups were asked to carry out the reading projects for four reading texts prescribed from straightforward course book (C1). Each group had four students and first, they were given the instruction to read four texts related to social diversities and humanities according to their respective groups. Then, they were asked to list the facts what they have read in reading record under the subtitles including the main idea of the text, supporting ideas of the text to extract social diversities and humanities by sharing and discussing within the relevant groups. After that, they were given the questions to interview for observing social diversities and humanities. Then, they were given feedback on the marks and data that they obtain from inter- 
viewing and listing in reading catalogues.

3) Giving four reading texts to the students to investigate social diversities and humanities and giving feedback to them

In the second two weeks, students from four groups were asked to carry out the reading projects for four reading texts prescribed from straightforward course book (C1). Each group had four students and first, they were given the instruction to read next four texts related to social diversities and humanities according to their respective groups. Then, they were asked to list the facts what they have read in reading monthly report under the subtitles including the main idea of the text, subordinating ideas of the text to extract social diversities and humanities by sharing and discussing within the relevant groups. After that, they were given the questions to interview for observing social diversities and humanities. Then they were given the feedback on the marks and results obtained from interviewing and listing in reading catalogues. After that, the teacher discussed with the students concerned all marks and data obtained from interviewing and listing in reading catalogues on the last day of observation period.

4) Collecting and analyzing data

In this section, all marks and data from interviewing and listing in reading catalogues were collected and analyzed with qualitative method. After analyzing, it was found that most of the reading texts, approximately $75 \%$ of them show diverse societies and humanities. But the rest of them, about $25 \%$ mention only diverse societies. In detail, six of the reading texts conveyed both social diversities but also humanities. Only two reading texts were included with social diversities.

\section{Findings and Discussion}

Based on collecting and analyzing data obtained through project-based learning approach, language used in selected reading texts can reveal different culture of the people. Besides, different diversities in society can be studied from selected eight reading texts. And also, due to the language which is the part of the society, the choice of words for action and emotion from selected reading texts can point out social diversities and humanities. Moreover, language from these texts can reflect the social life which is bounded with social diversities and humanities in alternative ways.

It can be shown that studying a target language or a foreign language is very beneficial not only for learners but also for teachers because all of them can observe and learn diverse societies and humanities in the language used in the selected reading texts. In brief, all outcomes from this research will be supportive for further research related to language, social diversities and humanities.

\section{Conclusion}

It is true that there is a connection between language and society, because different languages show different diversities and humanities. Otherwise, reading 
texts or approaching the literary texts can represent diversities and humanities in the society. Different diversities as well as humanities provide a means for communication among and between individuals and groups. On the other hand, reading and or reading texts can give chance to the readers to study social diversities and humanities. The general customs and manners of people greatly differ in the social diversities. Social diversities and humanities can determine the caste system, class, religion, occupational patterns in a given territory. Because of above benefits, the research paper attempted to teach the students selected reading texts prescribed from straightforward course book (C1) level to investigate social diversities and humanities through project-based learning approach in the EFL classrooms. This research took four weeks. As the targeted population and sample, twenty-eight Fourth-Year (COE) students including fourteen boys and fourteen girls from Yangon University of Education were involved in this research. This research was conducted through analytical approach by making observation and interviewing in groups as research tools. Data were collected and analyzed with qualitative research method. The outcomes from this research show that language used in selected reading texts can reveal more social diversities than humanities, comparing to the aspects of humanities to some extent. In brief, all outcomes from this research will be supportive for further research related to language, social diversities and humanities.

\section{Acknowledgements}

First and foremost, I would like to deeply thank Dr. Pyone Pyone Aung, Pro-rector, Yangon University of Education, Dr. Kay Thwe HLaing, Pro-rector, Yangon University of Education for giving me the opportunity to do this research.

Then, I am really grateful to Dr. Nyo Nyo Lwin, Professor and Head, the Department of English, Yangon University of Education for giving instructions to do this research.

\section{Conflicts of Interest}

The author declares no conflicts of interest regarding the publication of this paper.

\section{References}

[1] https://en.wikipedia.org/wiki/Politics

[2] https://gladstone.uoregon.edu/ asuomca/diversityinit/definition.html

[3] https://en.wikipedia.org/wiki/Project-based_learning

[4] Thomas, M. (2011) Project Based Learning. Teacher Greeno, J. G. (2006). Learning in Activity. In R. K.

[5] Blumenfeld, P.C., et al. (1991) Motivating Project-Based Learning: Sustaining the Doing, Supporting the Learning. Educational Psychologist, 26, 369-398.

[6] Hye-Jung Lee, H. and Cheolil Lim, C. (2012) Peer Evaluation in Blended Team 
Project-Based Learning: What Do Students Find Important? Journal of Educational Technology \& Society, 15, 214-224.

[7] http://www.ascd.org/publications/books/197166/chapters/The_Teacher's_Role_in_ Problem-Based_Learning

[8] Boss, S. and Krauss, J. (2007) Reinventing Project-Based Learning: Your Field Guide to Real-World Projects in the Digital Age. International Society for Technology in Education, Eugene, OR.

[9] Perrault, E.K. and Albert, C.A. (2017) Utilizing Project-Based Learning to Increase Sustainability Attitudes among Students. Applied Environmental Education \& Communication, 39, 38-42. 